\title{
Method Comparison of the Evaluation of the Cylindricity Deviation Measured by Different Measurement Strategies
}

\author{
Miroslav Dovica ${ }^{1 *}$, Ján Buša² \\ ${ }^{1}$ Department of Biomedical Engineering and Measurement, Faculty of Mechanical Engineering. Letná 9, 04200 Košice, Slovak Republic \\ ${ }^{2}$ Department of Mathematics and Theoretical Informatics, Faculty of Electrical Engineering and Informatics, Technical University of Košice, \\ Nèmcovej 32, 04001 Košice, Slovak Republic
}

\section{BIOGRAPHICAL NOTES}

Miroslav Dovica is a professor of metrology and a deputy head of the Department of Biomedical Engineering and Measurement. He has published 2 monographs, 2 university text books, 4 university notebooks and more than 160 publications in journals and conference proceedings in Slovakia and abroad. He raised a Laboratory of Coordinate Metrology for the Department of Biomedical Engineering and Measurement.

Ján Buša was born on 30. 6. 1958. In 1982, he graduated (RNDr) with distinction at the Department of Computational Physics at the Faculty of Numerical Mathematics and Cybernetics in Moscow State University in Russia. He defended his CSc in the field of Applied Mathematics in 1987; his thesis title was "Solving the Linear Systems with Inaccurate Given Data". Since 1986, he has been working as a teacher at the Department of Mathematics and Theoretical Informatics. His scientific research focuses on applied mathematics and numerical methods.

\section{KEY WORDS}

Cylindricity deviation, measurement strategy, linear least squares method (LLS), coordinate measuring machine (CMM).

\section{ABSTRACT}

The aim of this paper is to compare the quantitative parameters of methods used for the evaluation of the cylindricity deviation. Data is measured by the contact method using three different strategies for cylindricity measurement on the coordinate measurement machine (CMM) Contura G2, Carl Zeiss. For particular measurement strategies, the data is evaluated by Calypso 5.0 software (CMM) Contura G2 and Matlab/ Octave software. In order to compare the collected data, we use the parameters of possible axes positions of two coaxial cylinders and their least radial distance. In the last part of this paper, there is the discussion regarding obtained parameters of evaluating methods.

\section{Introduction}

Fine measurement of the cylindricity is complicated and it requires 3D Coordinate Measuring Machine (CMM). CMMs are equipped with the software that allows the operator to choose measurement parameters and evaluate associated features. Obtained accuracy of the measurement and time needed for the measurement are the 
important indicators, during repeated measurement in CNC regime. The choice of the measurement strategy influences economic effectiveness. The problem is how to set the strategy for the measurement of geometric features of parts and what associated integral features should be used for cylindricity evaluation. The real feature of part function is the criterion of selection of the particular associated feature when evaluating the measurement. Then, during the process of measurement strategy selection and the process of evaluation, the require-
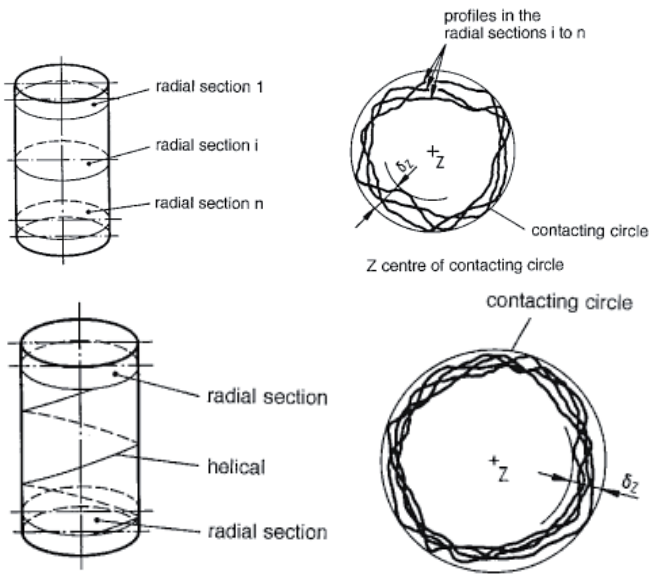

Fig. 1: Measurement strategies [2]

In metrological practice, in order to evaluate cylindricity, as shown in Figure 2, these four associated features are used: LSCY, MZCY, MICY (maximum inscribed) and MCCY (minimum circumscribed) cylinders. Each of these cylinders has its advantages and disadvantages $[3,4,5,6,7,8]$. Let us present experimental results of the cylindricity deviation analysis.
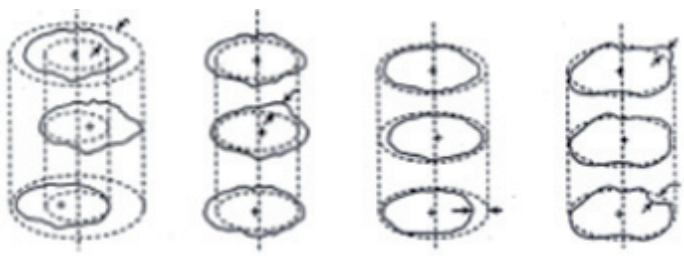

Fig. 2: An example of the associated features of cylindricity evaluation ( $a-M Z C Y, b-M I C Y, C-M C C Y, d-L S C Y)$.

\section{Experiment}

The measurement of cylindricity deviations was performed by CMM Contura G2 VAST XXT (see Figure 3 ) that is equipped with Calypso 5.0 software ments for measurement accuracy become crucial. It is highly recommended to measure in a way that a particular function of the part requires. Since there are no specific standard methods for the choice of the measurement strategy, the operator of the machine plays an important role [1].

As shown in the Figure 1, EN ISO 12180-2:2011 describes four measurement strategies, i.e. measurement strategy of roundness profiles, measurement strategy of generatrix lines, measurement strategy for helix, and points measurement strategy.
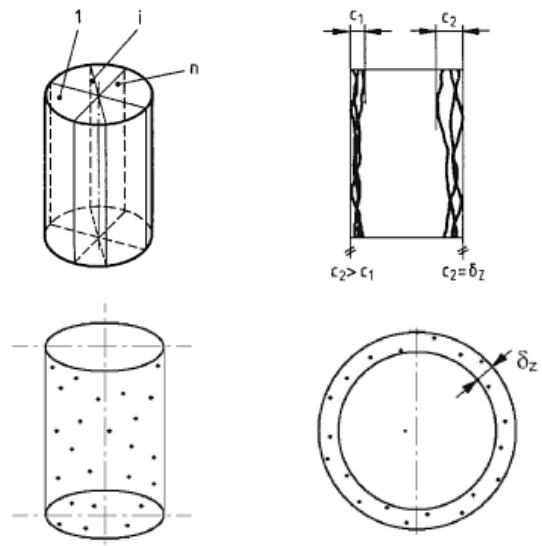

with following parameters:

- Maximum permissible error (MPE) for length measurement with Contura G2 (size 7/10/6) with RDS holder and VAST XXT sensor is MPEE $=(1,8+$ $L / 300$ ) $\mu \mathrm{m}$, where $L$ is measured length in $\mathrm{mm}$ (according to EN ISO 10360-2).

- Maximum permissible scanning probing error is $M P E T H P=3,5 \mu \mathrm{m}$ for required measuring time $68 \mathrm{~s}$ (according to EN STN ISO 10360-4).

- Maximum permissible error for form measuring is MPERONt $=1,8 \mu \mathrm{m}$ (according to EN ISO 12181 and VDI/VDE 2617 part 2.2).

Measured nominal diameter of parts equals to 20 $\mathrm{mm}$. A series of measurements was performed in scanning mode with the speed of $5 \mathrm{~mm} / \mathrm{s}$. Diameter of stylus type $-3 \mathrm{~mm}$, stylus length - $50 \mathrm{~mm}$.

Series of parts measurement, shown in Figure 4, was realised by three measurement strategies in scanning mode (see Figure 5).

Let us describe used measurement strategies:

- Measurement strategy of roundness profiles 165 measured points. 
- Measurement strategy of generatrix lines - 156 measured points.

- Measurement strategy for helix - 179 measured points.

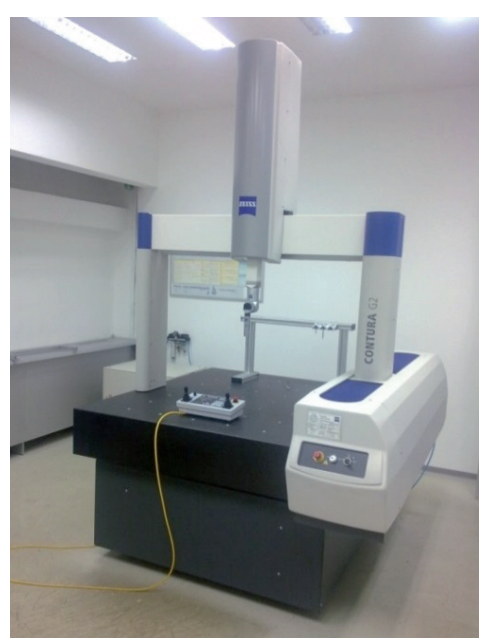

Fig. 3: Coordinate measuring machine, Carl ZEISS Contura G2 RDS.

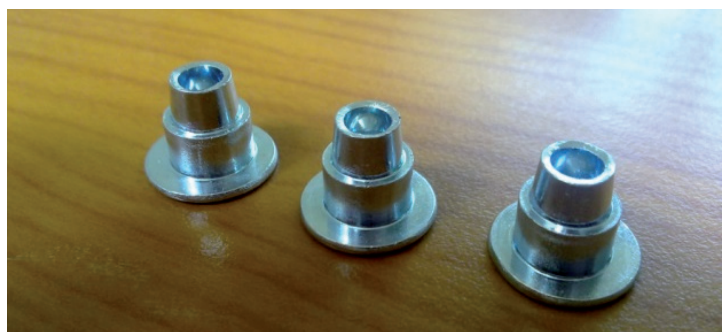

Fig. 4: Photo of measured parts

roundness profiles (165 points) generatrix lines (156 points) helix (179 points)

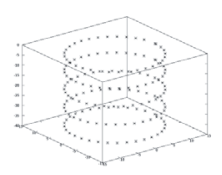

a)

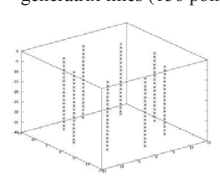

b)

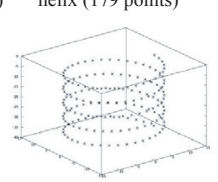

c)
Fig. 5: Measurement strategy of parts.

\section{Cylindricity Deviations Analysis}

When evaluating the circularity, we used standard definition of the tolerance zone, i.e. "The tolerance zone is limited by two coaxial cylinders with a difference in radii of tolerance."

According to ISO 1101:2004, the cylindricity deviation is a difference between the largest and the smallest radial distances of the part surface from associated cylinder. The position of axes of the cylinders and values of the radii must be chosen such that the difference between two coaxial cylinders of radii equals to the smallest possible value [3].
For the analysis of the measured data, we used Octave, Matlab and Calypso 5.0 software of CMM. The analysis was performed for the data obtained by three strategies (roundness profiles $(\mathrm{O})$, generatrix lines $(\mathrm{L})$ and helix $(\mathrm{H})$ ).

Parameter calculations of associated cylinders were realised in Octave or Matlab software in three ways:

1. Parameters of cylinders with vertical axis are set using Linear Least Square method (LLS) for which the sum of squares is minimal. In this case, the problem is reduced and circularity deviations are set by the coordinates of $x$ and $y$. This method is described in more details in [9].

2. The solution of this problem using LLS has been used as an initial approximation for determination of two perpendicular coaxial cylinders with the condition of minimum zone (ICMZ). Of course, this problem solving gives minimum deviation from cylindricity using LLS method.

3. Furthermore, the ICMZ serves as an initial approximation for the solution of coaxial cylinders with minimum zone (CMZ), this time from the tilted axis of symmetry. This problem was solved by the following function 0ctave and/or Matlab.

$$
\text { fminsearch('width_cylider',x0,opt), }
$$

where the unknown are the coordinates of points $x$ and $y$ intersecting the axis with the plane $z=z_{\text {min }}$ and $z=z_{\text {max }}$. These points are recorded in Table 1 as lower and upper centre. The cylindricity deviation obtained in this way, using CMZ method, is undoubtedly smaller that two above mentioned values computed for LLS and ICMZ methods.

Time is an important factor when using LLS, ICMZ and $\mathrm{CMZ}$ for computer calculations compared to the measurement itself. Therefore, we may suppose that the most accurate results are the results that provide the most complete information about a part, e.g. results of data processing for all 500 measured data. In the table, these results are denoted as SUM.

Calculated parameters using Octave and/or Matlab software are presented in Table 1.

\section{Conclusion}

The comparison of three different measurement strategies was performed using the cylindricity deviation. CMM Contura G2 is equipped with Calypso 5.0 software. Data analysis focused on the strategies of measurement. Outcome data from the programme are not sufficient for such analysis. In order 
Table 1: Calculated parameters.

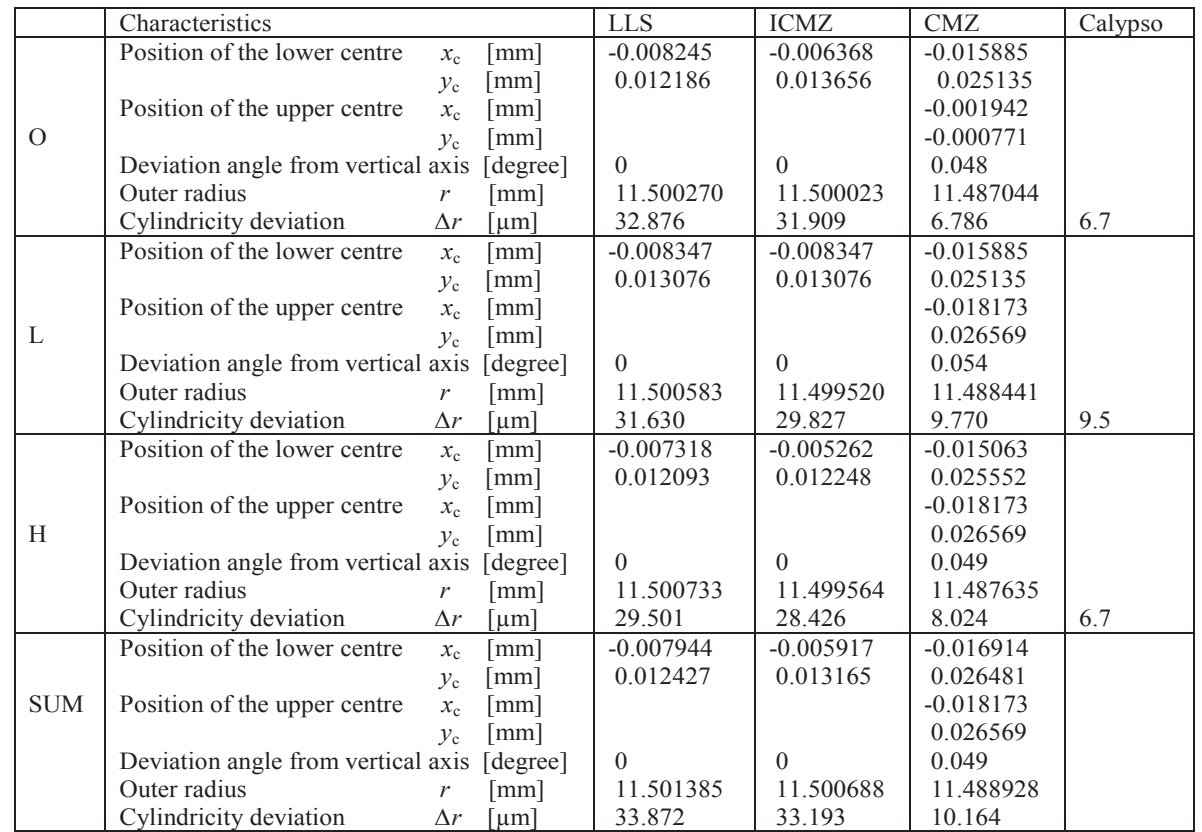

to compare the expedience and the efficiency of the measurement strategy, more information on quantitative indicators is necessary, e.g. measurement accuracy, time of measurement, part function, etc. This information can be obtained during further data processing. In this paper, we used Octave and Matlab software that produce more detailed information from the data obtained by the measurement.

Our results are presented in Table 1. The data was obtained by the tactile probe. Recommended speed of scanning and other requirements are set by the good practice measurement [1]. Despite these facts, we cannot definitely recommend either the expedience of used measurement strategy or the expedience of use of associated feature for cylindricity deviation evaluation.

Further research should focus on the solution of the influence of other factors that may bias the results of measurement. It may lead to a proposal of the classification of measurement principles defined in standards.

\section{Acknowledgements}

This work is part of a research project of the Slovak Republic VEGA 1/0085/12: New strategy for effective measurements with coordinate measuring machines with multi sensor systems and KEGA
005STU-4/2012: Virtual laboratory for 3D coordinate measurement.

\section{References}

[1] Flag D.: CMM measurement strategies. ISSN 1368-6550 NPL United Kingdom 2001

[2] Henzold G.: Geometrical Dimensioning and Tolerancing for Design, Manufacturing and Inspection. Elsevier Ltd. 2006

[3] ISO 12180-2:1999: Geometrical product specification (GPS) Cylindricity - Part 2: Specification operators.- Berlin: Beuth Verlag GmbH, 1999, 15 pp.

[4] Adamczak S.: Metrologia w budowie maszyn. Warszawa, Wydawnictwa Naukowo- techniczne, 2004,300 s. ISBN 978-83-2043526-9

[5] Majstrovič V., Hodolič J.: Numerički upravljane merne mašine. Novi Sad, Offset print, 1998, 183 s. ISBN 86-499-0091-7

[6] Chudý V., Palenčár R., Kureková E., Halaj M.: Meranie technických veličín. Vyd. STU, 1998 ISBN 80-227-1171-3

[7] Ákos A. Model of electronic moire equipment. Inf. Control. Syst. 2010;9:36-68.

[8] Adamczak S., Janecki D., Makiela W., Stepieň K.: Quantitative comparison of cylindricity profiles measured with different methods using legendre-fourier coefficients Metrol.Meas.Syst. Vol.XVII (2010), No.3.pp.397-404

[9] Довица М., Буша Я., Паленчар Р., Дюриш С., Шоош Л., Врба И., Шковранек Т., Келеменова Т.: Сравнение методов анализа отклонений круглости. Измерительная техника. 2013, №9, С. 25 27.(in Russian) 